\title{
Studies on the Nuclear Binding of Steroid Hormone- Receptor Complex; Binding of Liver and Thymus Dexamethasone-Receptor Complex and Prostate Dihydrotestosterone-Receptor Complex to Nuclei from Various Tissues
}

\author{
Noriko MURAKAMI ${ }^{1}$, Akio YOSHIDA ${ }^{2}$ AND Shogo ICHII ${ }^{1}$ \\ ${ }^{1}$ Division of Physiology, Institute of Steroid Research and \\ ${ }^{2} 1$ st Department of Internal Medicine, Tottori University \\ School of Medicine, Yonago, Tottori 683, Japan
}

\begin{abstract}
Synopsis
To examine the binding specificity of steroid hormone-cytoplasmic receptor complexes to nuclei, binding of ${ }^{3} \mathrm{H}$-dexamethasone (Dex)-liver, ${ }^{3} \mathrm{H}$-Dex-thymus and ${ }^{3} \mathrm{H}$ dihydrotestosterone (DHT)-prostate receptor complexes to nuclei from liver, prostate, thymus, spleen and kidney was studied. It was observed that a significant amount of steroid-receptor complexes was bound to any nuclei used in the present study and the extent of the binding of receptor complexes to nuclei from homologous tissues was not always greater than that to nuclei from heterogenous tissues. However, a significant portion of the ${ }^{3} \mathrm{H}$-Dex-liver and ${ }^{3} \mathrm{H}$-DHT-prostate receptor complexes was not absorbed by nuclei from kidney, spleen and thymus, and the unabsorbed complexes were efficiently bound to liver and prostate nuclei. The results obtained indicate that two types of receptor complex with regard to nuclear binding were present in cytosols of liver and prostate; one binds to nuclei from kidney, spleen, thymus, liver and prostate and the other does not bind to nuclei from kidney, spleen and thymus but does bind to nuclei of liver and prostate. The latter type of receptor complex was not observed in the cytosol from the thymus.
\end{abstract}

Translocation of the steroid hormonecytoplasmic receptor complex seems to be an obligatory step in the mechanism of steroid hormone action. However, many conflicting observations concerning the mode of binding of hormone-receptor complexes by nuclei have been reported. Lack of tissue specificity of the binding has been reported for the progesterone-receptor complex of chick oviduct (Buller et al., 1975; Jaffe et al., 1975), the estrogen-receptor complex of rat uterus (Chamness et al., 1973) and also for the androgen-receptor complex of rat ventral prostate (Ichii, 1975). On the other hand the interaction of glucocorticoid and liver cytosol with liver nuclei was postulated to be tissue specific (Milgrom and Atiger,

Received May 11, 1978
1975) and the enrichment of nuclear acceptor sites for the hormone-receptor complexes was observed in target tissues of progesterone (Jaffe et al., 1975), dihydrotestosterone (Fang and Liao, 1971), estrogen (Danzo et al., 1978) and glucocorticoids (Turnell and Burton, 1975). However, there have been other reports indicating that estrogen and androgen-receptor complexes bound to nuclei from various tissues in almost the same manner (Chamness et al., 1973; Ichii et al., 1977). In this way, the physiological significance of the nuclear binding of cytoplasmic steroid hormonereceptor complexes in the mechanism of steroid hormone action is not yet fully understood. In the present study, we examined the nuclear binding specificity for steroid hormone-receptor complexes using 
nuclei from liver, ventral prostate, kidney, spleen and thymus and cytoplasmic receptor complexes for dexamethasone (Dex) in liver and thymus and for dihydrotestosterone (DHT) in prostate to throw further insight into the physiological significance of the nuclear binding of steroid hormone-receptor complexes in the steroid hormone action.

\section{Materials and Methods}

\section{Animals and tissue preparations}

Livers, Kidneys and spleens were obtained from male Wistar rats weighing $200 \mathrm{~g}$. Thymuses and ventral prostates were removed from animals of the same strain and sex weighed 150 and $350 \mathrm{~g}$. To prepare the cytosol, tissues were homogenized in 3 volumes of buffer solution containing $10 \mathrm{mM}$ Tris$\mathrm{HCl}(\mathrm{pH} 7.4), 2 \mathrm{mM}$ 2-mercaptoethanol and $0.5 \mathrm{mM}$ EDTA (buffer A). The supernatant obtained after successive centrifugations of the homogenate at 600 $\times \mathrm{g}$ for $10 \mathrm{~min}, 8,000 \times \mathrm{g}$ for $20 \mathrm{~min}$ and $100,000 \times \mathrm{g}$ for $60 \mathrm{~min}$ was referred to as the cytosol. For preparation of nuclei, tissues were homogenized in 3 volumes of medium which consisted of $20 \mathrm{mM}$ Tris$\mathrm{HCl}$ (pH 7.4), $2 \mathrm{mM} \mathrm{CaCl}, 1 \mathrm{mM} \mathrm{MgCl}$ and $250 \mathrm{mM}$ sucrose (buffer B). The homogenate was centrifuged at $600 \times \mathrm{g}$ for $10 \mathrm{~min}$, pellets were resuspended in buffer $\mathbf{B}$ and resedimented by centrifugation at $100,000 \times \mathrm{g}$ for $60 \mathrm{~min}$ through a cushion of $1.7 \mathrm{M}$ sucrose according to the method of Blobel and Potter (1966). The nuclear fraction thus obtained was washed twice with buffer $\mathbf{B}$ before use.
Preparation of steroid-cytoplasmic receptor complexes

The liver and thymus cytosol were incubated in

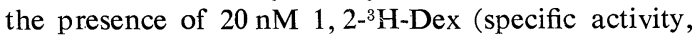
$24 \mathrm{Ci} / \mathrm{mmole}$ ) at $0^{\circ} \mathrm{C}$ for $4 \mathrm{hr}$. The cytosol from ventral prostate was incubated in the similar manner using $1,2-{ }^{3} \mathrm{H}-\mathrm{DHT}$ (specific activity, $175 \mathrm{Ci} / \mathrm{mmole}$ ). Unbound steroid was removed by dextran-charcoal. In this paper, the protein bound radioactive steroids which translocate to isolated nuclei under the incubation conditions used (see below) were tentatively referred to as the receptor complex. Labelled steroid receptor complexes prepared in the manner were used immediately for experiments. The labelled steroids used in the present study were obtained from The Radiochemical Centre, Amersham, England.

Determination of rate of the steroid-receptor
complex binding to nuclei Purified nuclei were suspended in buffer $\mathbf{B}$ and incubated with ${ }^{3} \mathrm{H}$-labelled cytosol at $30^{\circ} \mathrm{C}$ for $20 \mathrm{~min}$ in a final volume of $3.0 \mathrm{~m} l$. Amounts of nuclei and ${ }^{3} \mathrm{H}$-labelled cytosol used were described in legends to each Figure. After incubation, $5 \mathrm{ml}$ of ice-cold buffer B was added, the mixture was stirred gently and nuclei were recovered by brief centrifugation $\left(3,000 \times \mathrm{g}\right.$ for $10 \mathrm{~min}$ at $\left.4^{\circ} \mathrm{C}\right)$. This washing procedure was repeated 3 times. The nuclear bound steroid was extracted with $3 \mathrm{~m} l$ of ethanol twice and ethanol fractions were transferred to a counting vial. Ethanol was evaporated down and the radioactivity was determined.

\section{Analytical method}

DNA and protein were determined by the method

Fig. 1. Binding of cytoplasmic ${ }^{3} \mathrm{H}$-Dex-liver receptor complex to nuclei from liver, kidney, spleen, prostate, and thymus.

(a) ${ }^{3} \mathrm{H}$-Dex-labelled liver cytosol $(397,000 \mathrm{dpm})$ was incubated with kidney nuclei 3 times followed by 2 incubations with spleen nuclei. The receptor complex thus treated was finally incubated with liver nuclei twice. The bound radioactivity to each nuclear fraction was determined ( - ). Another portion of the labelled cytosol $(397,000 \mathrm{dpm})$ was treated with spleen nuclei ( 3 times), kidney nuclei (2 times) in the similar manner (----). The amount of nuclei used for each incubation was $0.65,1.2$ and $1.5 \mathrm{mg}$ (as DNA) for liver, kidney and spleen nuclei, respectively. For other details of the experimental conditions, see the text.

(b) ${ }^{3} \mathrm{H}$-Dex-labelled liver cytosol $(586,000 \mathrm{dpm})$ was incubated with liver nuclei $(4$ times $)$ and with thymus nuclei $(2$ times) ( $\longrightarrow$ ). The same amount of the labelled cytosol was treated similarly with thymus nuclei first (4 times) followed by 2 treatments with liver nuclei (----). The amount of nuclei used for each incubation was 1.1 and $1.7 \mathrm{mg}$ (as DNA) for liver and thymus, respectively. (c) ${ }^{3} \mathrm{H}$-Dex-labelled liver cytosol $(370,000 \mathrm{dpm})$ was incubated with prostate nuclei $(4$ times) and finally with liver nuclei (2 times), successively (-). In other incubations, the same amount of the labelled cytosol was treated stepwise with liver nuclei (4 times) followed by 2 treatments with prostate nuclei (----). The amount of nuclei used for each incubation was 0.7 and $0.4 \mathrm{mg}$ (as DNA) for liver and prostate nuclei, respectively. 
of Burton (1956) and Lowry et al. (1951), respectively. The radioactivity was determined in $10 \mathrm{~m} l$ of toluene counting fluid using a Tri-Carb liquid scintillation spectrometer with automatic external standardization for quenching correction.

\section{Results}

When ${ }^{3} \mathrm{H}$-Dex-labelled liver cytosol was incubated either with kidney nuclei or with spleen nuclei, significant amounts of the radioactivity were recovered with nuclei as a bound form (Fig. 1a). It required 4 changes with fresh nuclei to minimize the binding components bound to such nuclei in the incubation mixture; after the 4th treatment with nuclei, no significant binding to such nuclei was observed. Pretreated ${ }^{3} \mathrm{H}$-Dex-labelled liver cytosol with nuclei from kidney and spleen in this manner was finally incubated with liver nuclei. As seen in Fig. 1a, a significant amount of the radioactivity in the pretreated labelled liver cytosol was bound to liver nuclei. This indicated that some portion of the cytoplasmic ${ }^{3} \mathrm{H}$-Dex-liver receptor complex bound to liver nuclei was not bound to either kidney or spleen nuclei. Similarly, the ${ }^{3} \mathrm{H}$-Dex-liver receptor complex was bound to thymus nuclei to a significant extent, but with thymus nuclei all of the liver complex was not removed from the incubation mixture; after the 4th treatment with thymus nuclei, significant amount of the complex which has an ability to bind to liver nuclei still remained in the incubation mixture (Fig. 1b). However, under the similar incubation conditions, prostate nuclei removed almost all the liver receptor complex from the reaction mixture (Fig. 1c).

The receptor complex bound only to thymus nuclei was not observed. Almost all the ${ }^{3} \mathrm{H}$-Dex-thymus receptor complex was eliminated from the incubation mixture by repeated treatments with nuclei from any tissues used in the present study (Fig. $2 a-c)$.

On the other hand, the ${ }^{3} \mathrm{H}$-DHT-prostate receptor complex was not removed completely from the reaction mixture by treatments with nuclei from thymus, kidney and spleen (Figs. $3 \mathrm{~b}$ and $\mathrm{c}$ ). However, treatments of the ${ }^{3} \mathrm{H}$-DHT-labelled prostate cytosol with liver nuclei removed almost all the complex bound to prostate nuclei from the reaction mixture (Fig. 3a). (a).

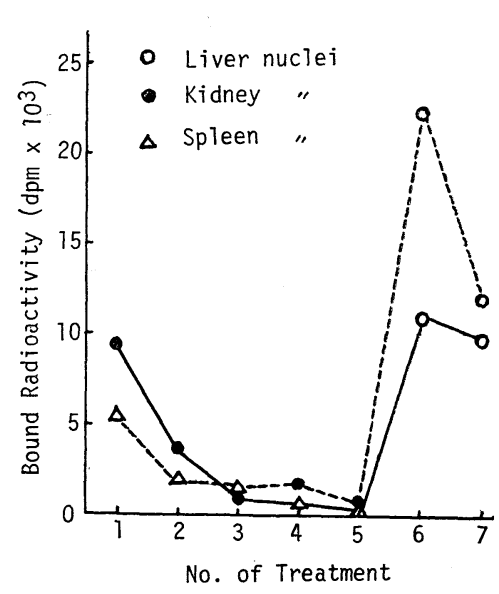

(b)

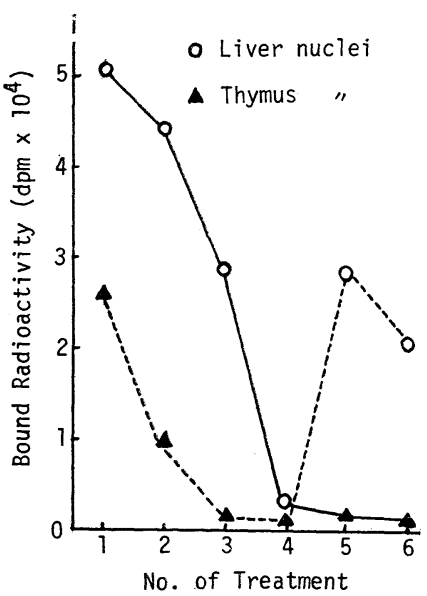

(c)

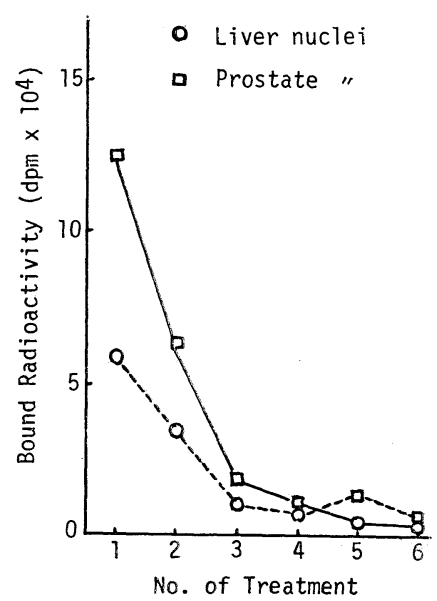


(a)

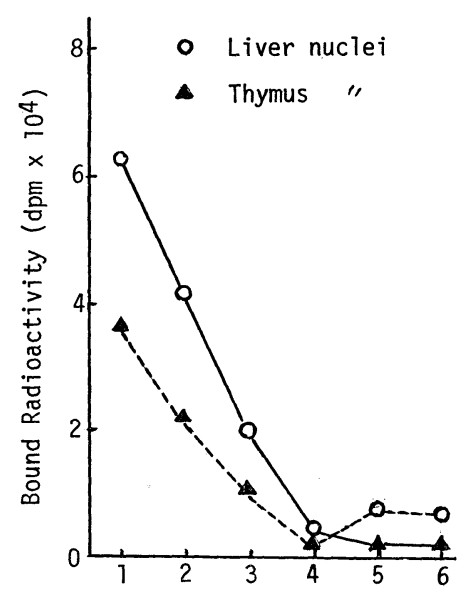

No. of Treatment (b)

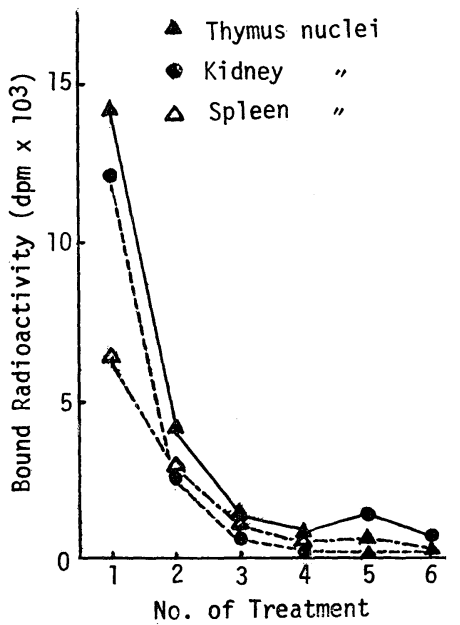

(c)

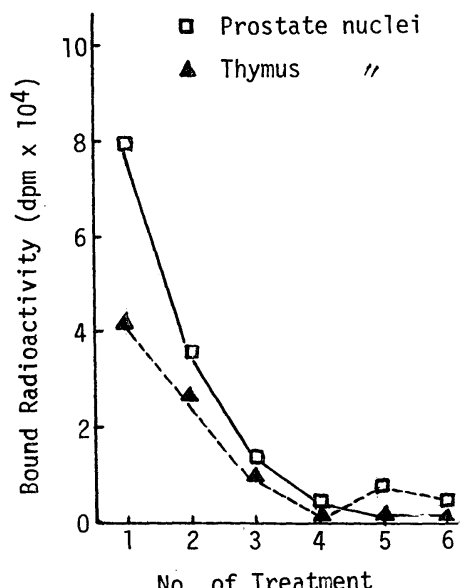

Fig. 2. Binding of cytoplasmic ${ }^{3} \mathrm{H}$-Dex-thymus receptor complex to nuclei from"liver, kidney, spleen, prostate and thymus.

(a) ${ }^{3} \mathrm{H}$-Dex-labelled thymus cytosol $(423,000 \mathrm{dpm})$ was incubated with liver nuclei (4 times) and then with thymus nuclei (2 times) (__ $)$. The same amount of the labelled cytosol was incubated with thymus nuclei first ( 4 times) followed by 2 treatments with liver nuclei $(-----)$. The amount of nuclei used for each incubation was 1.1 and $1.7 \mathrm{mg}$ (as DNA) for liver and thymus nuclei, respectively.

(b) ${ }^{3} \mathrm{H}$-Dex-labelled thymus cytosol $(201,000 \mathrm{dpm})$ was incubated with thymus nuclei (4 times) followed by 2 treatments with kidney nuclei (__ - ). The same amout of the labelled cytosol was incubated similarly with kidney and thymus nuclei (-- - ) and spleen and thymus nuclei (-- - $)$, respectively. The amount of nuclei used for each incubation was $1.7,1.8$ and $1.9 \mathrm{mg}$ (as DNA) for thymus, kidney and spleen nuclei, respectively.

(c) ${ }^{3} \mathrm{H}$-Dex-labelled thymus cytosol $(201,000 \mathrm{dpm})$ was incubated with prostate nuclei $(4$ times) and then with thymus nuclei (2 times) (- - - . The same amount of the labelled cytosol was incubated with thymus nuclei first (4 times) followed by treatments with prostate nuclei (-----). The amount of nuclei used for each incubation was 0.4 and $0.7 \mathrm{mg}$ (as DNA) for nuclei from prostate and thymus, respectively.

(a)

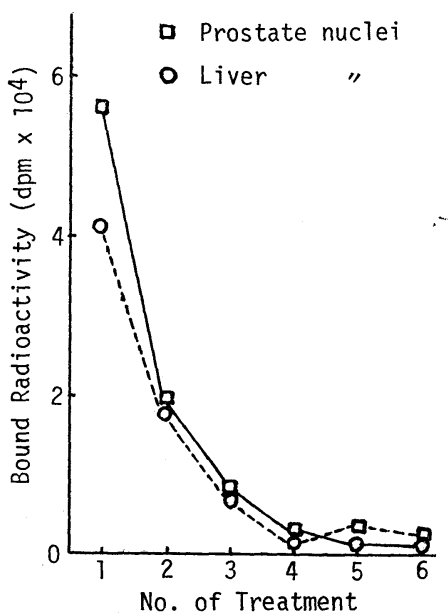

(b)

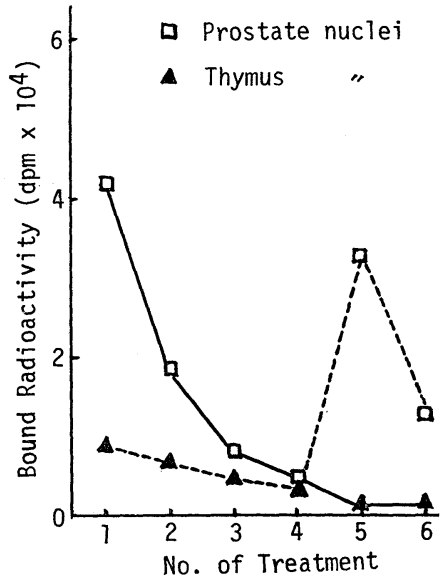

(c)

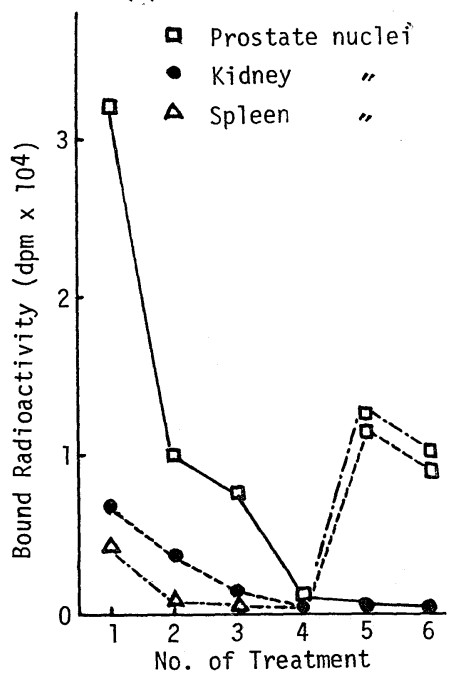




\section{Discussion}

Interaction of hormone-receptor complexes with nuclei seems to be a key step in the mechanism of steroid hormone action and many investigations have been performed on the nuclear binding of steroid hormone-receptor complexes in vitro. However, the mode of nuclear binding of hormone-receptor complexes has been the subject of controversy for many years. Several groups have shown that nuclei from target tissues bind cytoplasmic receptors to a greater extent than do nuclei from nontarget tissues (Danzo et al., 1978; Fang and Liao, 1971; Geschwendt and Hamilton, 1972; Mushliner et al., 1970; Steggles et al., 1971; Turnell and Burton, 1975). On the other hand, other investigators postulated that steroid hormone-receptor complexes bound almost equally to nuclei from various tissues (Buller et al., 1975; Chamness et al., 1973; Ichii, 1975; Yamamoto and Albert, 1975).

In the present study, it was observed that the significant amount of steroid hormone-receptor complexes from liver, thymus and prostate bound to any nuclei from liver, prostate, kidney, spleen and thymus. Furthermore, the extent of binding to nuclei from homologous tissues was not always greater than that to nuclei from heterogenous tissues. However, it was found that the significant portion of the ${ }^{3} \mathrm{H}$-Dex-liver receptor complex and that of the ${ }^{3} \mathrm{H}-\mathrm{DHT}$ prostate receptor complex were not eliminated from the reaction mixture after extensive absorption with nuclei from kidney, spleen and thymus (Figs. 1a, 1b, 3b and 3c). Heterogeneity of steroid hormone receptor was revealed in some tissues (Agarwal, 1975 and 1976; Agarwal and Phillipe, 1977), so it might be quite probable that the different component in preparations of steroid hormone-receptor complexes behaved differently in the nuclear binding. In the ${ }^{3} \mathrm{H}$-Dex-labelled liver cytosol, some component(s) bound to nuclei from kidney, spleen and thymus but there was (were) observed other component(s) which did not bind to nuclei from kidney, spleen and thymus but did bind to nuclei from liver and prostate. The similar nuclear binding component(s) was (were) also observed in the preparation of ${ }^{3} \mathrm{H}-\mathrm{DHT}$-labelled prostate cytosol, which did not bind to nuclei from kidney, spleen and thymus but bound to nuclei from prostate and liver. To examine differences in physiological properties of receptor complexes which showed different characteristics of the nuclear binding, stimulation of RNA-polymerase in the rat ventral prostate by the DHT-prostate receptor complex was studied. However,

\section{ڤ}

Fig. 3. Binding of cytoplasmic ${ }^{3} \mathrm{H}-\mathrm{DHT}$-prostate receptor complex to nuclei from liver, kidney, spleen, prostate and thymus.

(a) ${ }^{3}$ H-DHT-labelled prostate cytos $01(262,000 \mathrm{dpm})$ was incubated with prostate nuclei $(4$ times) and then with liver nuclei (־ $(-)$. The similar incubations were carried out using liver nuclei first followed by with prostate nuclei (---). The amount of nuclei used for each incubation was 0.4 and $0.7 \mathrm{mg}$ (as DNA) for prostate and liver nuclei, respectively.

(b) ${ }^{3}$ H-DHT-labelled prostate cytosol $(194,000 \mathrm{dpm})$ was incubated with prostate nuclei (4 times) and then with thymus nuclei (- $)$. The similar incubations were carried out using thymus nuclei first and then prostate nuclei (----). The amount of nuclei used for each incubation was $0.4 \mathrm{mg}$ (as DNA) for both tissues.

(c) ${ }^{3} \mathrm{H}-\mathrm{DHT}$-labelled prostate cytosol $(123,000 \mathrm{dpm})$ was incubated with prostate nuclei (4 times) and then with kidney nuclei (- $(-)$ In the other incubations, incubations with kidney nuclei (--) or spleen nuclei (_- - were carried out first and then with prostate nuclei. Amounts of nuclei used for each incubation were $0.5,0.8$ and $1.6 \mathrm{mg}$ (as DNA) for prostate, kidney and spleen, respectively. 
this attempt was not successful, since, in our hand, no significant stimulation of RNApolymerase in the rat ventral prostate was obtained even with the DHT-prostate receptor complex which was not pretreated with heterogenous nuclei under the similar incubation conditions described by Davies and Griffiths (1973) (data not shown). Comparison of other properties of the receptor complex "absorbed" by heterogenous nuclei with those of the "unabsorbed" one in liver and prostate is under examination in this laboratory.

In the present study, any evidences for the presence of tissue-specific receptor complex with regard to the nuclear binding were not obtained. Therefore, a question how the great selectivity in receptor action is achieved despite an apparently weak selectivity in nuclear binding of receptor complexes has arisen. Since the interaction of hormone-receptor complexes with nuclei seems to be an obligatory step in the mechanism of steroid hormone action, this question has to be answered to gain further insight into the mechanism of steroid hormone action.

\section{References}

Agarwal, M. K. (1975). Nature 254, 623.

Agarwal, M. K. (1976). FEBS Letters 62, 25.

Agarwal, M. K. and M. Philippe (1977). Biochim. Biophys. Acta 500, 42.

Blobel, G. and V. R. Potter (1966). Science 154, 1662.

Buller, R. E., D. O. Toft, W. T. Schrader and B. W. O'Malley (1975). J. Biol. Chem. 250, 801.

Burton, K. (1956). Biochem. J. 62, 315.

Chamness, G. C., A. W. Jennings and W. L. McGuire (1973). Nature 241, 458.

Danzo, B. J., W. Sutton and B. C. Eller (1978). Mol. Cell. Endocr. 9, 291.

Davies, P. and K. Griffiths (1973). Biochem. J. 136, 611.

Davies, P. and K. Griffiths (1974). J. Endocrin. 62, 385.

Fang, S. and S. Liao (1971). J. Biol. Chem. 241, 16.

Geschwendt, M. and T. H. Hamilton (1972). Biochem. J. 128, 611.

Ichis, S., N. Murakami and M. Izawa (1977). $J$. Biochem. 81, 897.

Jaffe, R. C., S. H. Sochor and B. W. O'Malley (1975). Biochim. Biophys. Acta 339, 403.

Lowry, O. H., N. J. Rosebrough, A. L. Farr and R. J. Randal (1951). J. Biol. Chem. 193, 265.

Milgrom, E. and M. Atiger (1975). J. Steroid Biochem. 6, 487.

Mushliner, T. A., G. V. Chader and C. A. Villee (1970). Biochemistry 9, 4448.

Steggles, A. W., T. C. Spelsberg, S. R. Glasser and B. W. O'Malley (1971). Proc. Nat. Acad. Sci. USA. 68, 1479.

Turnell, R. W. and A. F. Burton (1975). Mol. Cell. Biochem. 9, 175.

Yamamoto, K. R. and B. Albert (1975). Cell 4, 301. 